Introduction Public administration challen ges frustrate the distribution of condoms in PNG. Whereas HIV/AIDS-awareness and condom-use programs can be undertaken as resources permit, realising universal access means distributing condoms in ways more resilient to the vulnerabilities experienced by state agencies.

Methods The PNG Companion Product Condom Distribution Project seeks to evaluate the viability of distributing condoms by piggybacking on existing supply-chains. It is funded by the PNG National AIDS Council Secretariat (NACS) and advanced in cooperation with a national distributer of a popular laundry soap.

An initial study evaluated the receptiveness of trade-store proprietors to receiving condoms via companion packaging. The study comprised interviews with 100 storeowners randomly selected from four administrative areas. Cooperating storeowners were provided with 200 free condoms during the first interview, and informed they could either sell or give these away. After 10 days, enumerators returned to conduct follow-up interviews. Results Of the 100 storeowners surveyed, only 2 indicated they had regularly stocked condoms in the past. Ninety-five agreed to distribute the free condoms and 88 later provided valid data indicating that of the 17,600 condoms distributed to these storeowners, 216 had been sold and 6,915 given away by the time enumerators returned. Interest in receiving further free supplies via companion packaging was indicated by 88 storeowners, most referring to the ease of this approach as a means of providing their communities with access to condoms.

Conclusion The results suggest that the market for condoms in villages remains immature but that the approach has potential both as a means of distributing condoms and as a means of introducing them to the village-store level. A trial distribution in two provinces is currently underway.

Disclosure of interest statement The PNG Companion Product Condom Distribution Project is a Public Private Partnership with coordination, monitoring and evaluation supported by the PNG National AIDS Council Secretariat. A Behavioural Change and Education component is provided by UNFPA. Colgate Palmolive collaborate through making available their supply chain, which reaches from their Lae warehouse to the trade-store level of the national economy.

\section{P13.02 FEMALE GENITAL COSMETIC SURGERY TOOLKIT FOR GENERAL PRACTITIONERS AND OTHER HEALTH PROFESSIONALS}

Magdalena Simonis*. Royal Australian College of General Practitioners, Fellow, Co-Chair Women in General Practice, General Practice and Primary Health Care Academic Centre, University of Melbourne, Victorian Primary Care Practice-Based Research Network (VicReN), Melbourne, Victoria, Australia

\subsection{6/sextrans-2015-052270.500}

Background Female Genital Cosmetic Surgery (FGCS) is any procedure not medically indicated which aims to achieve aesthetic or functional aspects a woman's genitalia. ${ }^{1}$ Figures from Medicare Australia indicate the number ow women undergoing FGCS has increased 140 percent in the past ten years (www. medicareaustralia.gov.au/statistics/mbs_item.shtml), with out rise in the indigence of disease conditions that warrant surgery. The fastest increase is in women aged $15-25$ years. $^{2}$ GPs are increasingly seeing patients presenting with concerns about the appearance of their genitalia and or seeking surgery. RACGP has responded by agreeing to the development of the FGCS Toolkit for GPs and other health professionals. Reviewers include key international researchers.

Aims To inform GPs and health professionals around FGCS, factors influencing demand and provide a set of recommendations on how to manage women who present for referral or expressing concern regarding their genital appearance.

Method Medline and PubMEd were searched for relevant articles until saturation was achieved in 2015. These were then hand searched. Time frame restrictions were not applied.

Results There is paucity of high quality evidence in the area of FGCS therefore all recommendations in this document should be considered at national Health and medical Research Council (NHMRC) practice point level.

Conclusion Claiming demand for FGCS in the community has resulted int the urgent need to provide guidance to the profession. There are similatrities in the rate of increase for FGCS in the UK, USA and western Europe. As research continues, it will serve to expand and broaden our understanding of the issues raised.

Disclosure of interest statement RACGP fellow and National Standing Committee member Quality Care Women's Health Victoria Board member.

\section{REFERENCES}

1 Bramwell R, Morland C, Garden AS. Expectations and experience of labial reduction: a qualitative study. BJOG Int J Obstet Gynaecol. 2007:114:1493-99

2 McDougall LJ. Towards a clean slit: how medicine and notions of normality are shaping female genital aesthetics. Cult Health Sex. 2013;15:774-87.

\section{P13.03 TARGETED PRIMARY HEALTH CARE AND SEXUAL HEALTH SERVICES CAN DELIVER THE HEPATITIS C STRATEGY: ONE YEAR OF FIBROSCANS AT THE KIRKETON ROAD CENTRE (KRC)}

${ }^{1} \mathrm{R}$ Gilliver*, ${ }^{1} \mathrm{~K}$ Scholey, ${ }^{1} \mathrm{~K}$ Chronister, ${ }^{1,2}$ | van Beek, ${ }^{1,3} \mathrm{P}$ Read. ${ }^{1}$ Kirketon Road Centre, Kings Cross, NSW, Australia; ${ }^{2}$ School of Public Health and Community Medicine, UNSW Australia, NSW, Australia; ${ }^{3}$ The Kirby Institute, UNSW Australia, NSW, Australia

\subsection{6/sextrans-2015-052270.501}

Introduction National and NSW Hepatitis C (HCV) strategies identify primary health care and sexual health services as crucial for expanded assessment and treatment of HCV. KRC is a targeted primary health care facility in Sydney's Kings Cross, involved in the prevention, treatment and care of HIV, STIs and viral hepatitis to people who inject drugs. Since April 2014 KRC has used a portable fibroscan on site and at outreach clinics held at The Langton Centre (drug and alcohol service), NSW Users and AIDS Association, the Medically Supervised Injecting Centre, and the Sydney Sexual Health Centre to assess clients for liver disease. The aim of this study was to describe clients receiving a fibroscan during the first year, their fibroscan results and retention in care.

Methods All clients who underwent a fibroscan from April 2014 through March 2015 were included. Clients' demographics, fibroscan results, HCV genotype, HIV co-infection and followup data were analysed.

Results Fibroscans were performed among 161 clients: 106 male, 51 female, 4 transgender. Median age was 43, and 12 (7\%) identified as Aboriginal; 146 (91\%) reported having injected drugs; $72 \%(\mathrm{n}=116)$ were HCV PCR positive $(58 \%$ genotype 1 , 38\% genotype 3; 7 were HIV co-infected); 17 were hepatitis B sAg positive (1 HIV co-infected); 28 were of unknown status. Fibroscans showed F0-1 liver fibrosis in 105 $(65 \%), \mathrm{F} 2=28(17 \%), \mathrm{F} 3=16(10 \%)$ and $\mathrm{F} 4=12(8 \%)$. 